\title{
Bidirectional Shunt Trajectory in Ventricular Septal Defect With Eisenmenger's Syndrome
}

Hiromi Kayamori, MD; Takeshi Kashimura, MD, PhD; Yosuke Horii, MD, PhD;

Tsutomu Kanazawa, PhD; Toshio Fujita, MD, PhD; Naoki Kubota, MD; Yasuhiro Ikami, MD;

Toshiki Takano, MD; Takeshi Okubo, MD; Makoto Hoyano, MD, PhD; Takao Yanagawa, MD, PhD;

Takuya Ozawa, MD, PhD; Kazuyuki Ozaki, MD, PhD; Tohru Minamino, MD, PhD
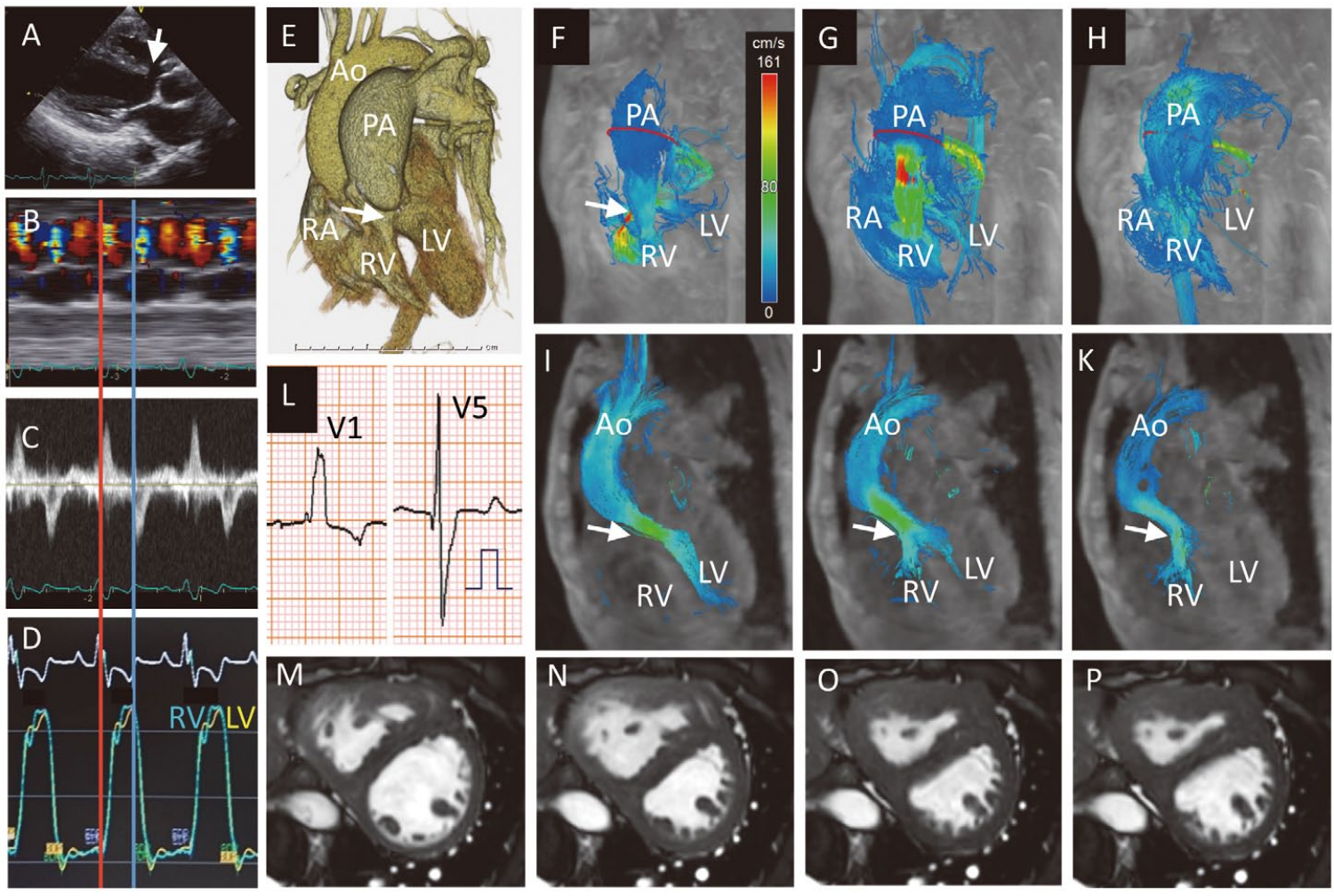

Figure. (A) Transthoracic echocardiography showed a membranous ventricular septal defect (arrow), (B,C) early systolic left-toright shunt, and late systolic right-to-left shunt, on (B) color and (C) pulsed wave Doppler. (D) Simultaneous right and left ventricular (RV and LV) pressure measurements. (E) Left anterior oblique (LAO) contrast-enhanced 3-D computed tomography. $(\mathbf{F}-\mathbf{H})$ LAO view of the trajectory of the pulmonary artery (PA) blood flow visualized on 4-D flow magnetic resonance imaging (MRI) by locating the region of interest (red circle) surrounding the main PA (F, early; $\mathbf{G}$, mid; and $\mathbf{H}$, late systole, respectively). (I-K) Cross-sectional 4-D flow MRI of blood flow in the aorta (Ao; I, early; $\mathbf{J}$, mid; and $\mathbf{K}$, late systole, respectively). (L) Electrocardiogram $(0.5 \mathrm{mV} / \mathrm{cm})$. (M-P) Cine mode MRI (M, end diastole; $\mathbf{N}$, LV contraction prior to RV; $\mathbf{O}$, contraction of the LV and RV; $\mathbf{P}, \mathrm{LV}$ dilation prior to RV). RA, right atrium.

Received March 19, 2018; revised manuscript received April 13, 2018; accepted April 18, 2018; released online May 25, 2018 Time for primary review: 23 days

Department of Cardiovascular Biology and Medicine (H.K., T. Kashimura, N.K., Y.I., T.T., T. Okubo, M.H., T.Y., T. Ozawa, K.O., T.M.), Department of Advanced Cardiopulmonary Vascular Therapeutics (T. Kashimura, M.H.), Department of Radiology (Y.H., T. Kanazawa), Niigata University Graduate School of Medical and Dental Sciences, Niigata; Division of Cardiology, Nagaoka Red-Cross Hospital, Nagaoka (T.F.), Japan

Mailing address: Takeshi Kashimura, MD, PhD, Department of Cardiovascular Biology and Medicine, Niigata University Graduate School of Medical and Dental Sciences, 1-754 Asahimachi, Niigata 951-8510, Japan. E-mail: kashi@med.niigata-u.ac.jp

ISSN-1346-9843 All rights are reserved to the Japanese Circulation Society. For permissions, please e-mail: cj@j-circ.or.jp 
A

64-year old man with ventricular septal defect (VSD) and Eisenmenger's syndrome was admitted to hospital with declining arterial $\mathrm{O}_{2}$ saturation. Transthoracic echocardiography showed a membranous VSD (Figure A), early systolic left-to-right shunt, and late systolic right-to-left shunt, on color (Figure B) and pulsed wave Doppler (Figure C). Simultaneous right and left ventricular (RV and LV) pressure measurements (Figure D) did not explain the timing of the bidirectional shunt flows. Left anterior oblique (LAO) contrast-enhanced 3-D computed tomography (Figure E) was helpful in confirming the anatomical orientation. 4-D flow magnetic resonance imaging (MRI) was then used to visualize the trajectory of flows in the pulmonary artery (PA) by locating the region of interest surrounding the main PA (Figure $\mathbf{F}-\mathbf{H}$; Movie S1). PA flow arose mainly from the LV via the VSD (arrow) at the beginning of systole (Figure F), subsequently also from the right atrium (RA; Figure G), and then from the RA alone (Figure H). Cross-sectional 4-D flow MRI of the aorta showed that the flow arose only from the LV at the beginning of systole (Figure I), subsequently from both the LV and RV (Figure $\mathbf{J}$ ), and then from the RV alone via the VSD (Figure K; Movie S2). Electrocardiogram showed right bundle branch block (Figure L), and cine mode MRI elucidated the time gap between LV and RV contraction, indicating the mechanism underlying the changing directions of flow and decline in arterial $\mathrm{O}_{2}$ saturation.

\section{Disclosures}

The authors declare no conflict of interest.

\section{Supplementary Files}

Supplementary File 1

Movie S1. 4-D flow MRI of PA flow. Supplementary File 2

Movie S2. 4-D flow MRI of Ao flow.

Please find supplementary file(s); http://dx.doi.org/10.1253/circj.CJ-18-0332 